\title{
Professional Development Needs for Educators Working with Children with Autism Spectrum Disorders in Inclusive School Environments
}

\author{
Penny Corkum, Susan E. Bryson, Isabel M. Smith \\ Dalhousie University \\ Cynthia Giffen, Kym Hume \\ Annapolis Valley Regional School Board \\ Ann Power \\ Nova Scotia Department of Education
}

\begin{abstract}
The primary objective of this mixed methods study was to identify educators ' professional development needs to determine how best to support them in providing quality programming for children with Autism Spectrum Disorders (ASD) within an inclusive educational system. Information was collected through focus groups with key school board informants $(n=33)$ and a survey of educators $(n=225)$. The results indicate that educators have found it difficult to meet the wide-ranging and varying needs of children with ASD within a strictly defined model of inclusive education. Educators consistently emphasized the need for multileveled and multipronged professional development that is accessible in a timely fashion and available as needs arise. The need for educational programs that work for children with ASD being taught within inclusive education settings is highlighted.
\end{abstract}

Autism Spectrum Disorders (ASD) are complex, lifelong neurobiological disorders that emerge early in a child's development. They are the most common of the severe disorders of development. While severity varies, at least 1 in every 160 children is affected, based on global estimates (Elsabbagh et al., 2012), with an even higher rate reported recently (Autism and Developmental Disabilities Monitoring Network, 2012). Current conceptualizations of ASD emphasize qualitative differences in social-communication skills, in addition to restricted, repetitive, and inflexible patterns of behaviour (Lord \& Jones, 2012). In addition to these defining features, cognitive, sensory, and motor systems, and more generally, the acquisition of independent adaptive skills, are affected in ASD. These impairments, together with high rates of both externalizing and internalizing problem behaviour (Horner, Carr, \& Strain, 2002), significantly affect the attainment of educational goals (National Research Council, 2001; Osborne \& Reed, 2011). Indeed, children 
with ASD may be seen as among the children most difficult to serve in educational systems (Bryson, Rogers, \& Fombonne, 2003; Emam \& Farrell, 2009; Humphrey, 2008). Lack of success in both the academic and social realms of education have major long-term implications for the health (i.e., physical, mental, and social well-being; World Health Organization, 1946) of affected children and their families. Moreover, the education of these children places significant stress on school personnel and thus impacts the health of educators (Emam \& Farrell, 2009).

The main goal of education is to provide opportunities for the acquisition of knowledge and skills that support personal independence and social responsibility (Kavale \& Forness, 1999). For children with ASD and other severe developmental disorders, the attainment of this goal is challenging and typically involves teaching specific sub-goals (e.g., basic social skills) that are not part of the standard curriculum. This challenge is complicated further by the wide variability in the expression of ASD and the need for highly individualized programs to meet the children's diverse needs. One of the most significant challenges that educators face within the public school system related to the education of children with ASD is the delivery of evidencebased practices within an inclusive education model.

A substantial body of research exists on the treatment and education of children with ASD. Research has identified specific instructional strategies that are effective in teaching children with ASD (National Autism Centre, 2009a), most of which draw on the principles of applied behaviour analysis (Baer, Wolf, \& Risley, 1968, 1987). Strong evidence of which interventions are best-suited to which children with ASD remains elusive, and the application of evidence-based practices requires a high degree of individualization (for a recent review as well as educationoriented guidelines, see National Autism Centre, 2009a, 2009b; see also Odom, Boyd, Hall, \& Hume, 2010a, 2010b)

Yet, despite the existence of these evidence-based practices, researchers (e.g., Emam \& Farrell, 2009) have found that educators still feel significant tension in attempting to deliver research-based strategies within an inclusive class environment. Furthermore, it has been found that some educators have mixed feelings regarding the effectiveness of inclusion-based programming, as well as uncertainty as to how to make inclusion work for children with moderate to severe ASD (Barnett \& Monda-Amaya, 1998; Praisner, 2003).

Educators' beliefs regarding the efficacy of inclusion-based curricula correlate positively with their level of training and/or professional development. For example, Jerlinder, Danermark, and Gill (2010) found that teachers who have access to sufficient training related to ASD demonstrate a more positive view of inclusion-based teaching strategies. Numerous authors (e.g., Kavale \& Forness, 1999; Salend \& Duhaney, 1999) have documented teachers' concerns over the lack of suitable training and/or professional development related to teaching children with ASD. For example, Swiezy, Stuart, and Korzekwa (2008) argued that preparing qualified teachers and paraprofessionals to educate and support students with ASD is the most significant challenge facing the autism field. In some jurisdictions, endorsement among stakeholders (teachers, administrators, parents) is high for specialized services delivered in "autism classrooms" (Callahan, Henson, \& Cowan, 2008). Elsewhere, some studies indicated that students with ASD make less progress in mainstream than in specialized settings (e.g., Reed, Osborne, \& Waddington, 2012). These findings suggest that educators' professional development needs pertaining to children with ASD may differ depending on whether they work within models of educational provision that do or do not emphasize inclusion.

The roles and training of paraprofessionals (i.e., "teaching assistants," "educational program assistants") have also been studied. Rispoli, Neely, Lang, and Ganz (2011) reviewed nine 
studies in which 22 school-based paraprofessionals were taught to implement various evidencebased practices for children with ASD. The specific methods and intensity of instruction of the paraprofessionals varied considerably depending on the skills being taught, but intervention settings (inclusive vs. special education) were not described. The authors concluded that literature is lacking with regard to the critical components of training required to teach different intervention strategies to teaching assistants. As with teachers, the contexts in which paraprofessionals work with students with ASD may determine what skills are needed and how best to impart these.

Thus, further research is needed concerning the professional development needs of educators-classroom teachers, specialists, paraprofessionals-who work in inclusion-based curriculum models with children with ASD. Educators' own identification of these needs is one key to promoting "buy-in" to professional development opportunities (Callahan et al., 2008).

The current mixed methods study focuses on the professional development needs of educators teaching children with ASD in inclusive classrooms. This research design allowed us to capture the complexities of these professional needs through qualitative research and then employ a quantitative research design to help generalize the findings. The study was a two-staged collaborative process between researchers based at Dalhousie University and educators within the Annapolis Valley Regional School Board and the Nova Scotia Department of Education. First, a review of provincial and school board educational policy documents, as well as documentation of past and current services provided to children with ASD provided the background information necessary to set the context for the following two stages. Stage 1 consisted of focus groups with key stakeholders (i.e., school administrators, resource teachers, and Student Services support staff) and was conducted in order to understand the needs of professionals working with students with ASD in inclusive classroom settings. Qualitative data gained from these focus groups informed the development of a survey for the second stage of the study. In stage 2, teachers and teaching assistants (TAs) were surveyed regarding their prior training and experience, professional development needs related to the instruction of students with ASDs in inclusive classroom settings, as well as their preferences regarding training methods/formats.

\section{Methods and Results}

\section{Background Information}

Nova Scotia is one of the Maritime Provinces of Canada and has a population of 950,000. Eight school boards within Nova Scotia serve more than 135,000 students from grade primary (one year of kindergarten) to Grade 12. In Canada, no federal legislation regulates education; rather, this is the responsibility of each province. In the relevant legislation in Nova Scotia, the importance of inclusive environments is clearly highlighted: "...develop and implement educational programs for students with special needs within regular instructional settings with their peers in age, in accordance with the regulations and the Minister's policies and guidelines"(Education Act, Statutes of Nova Scotia 1995-1996, section 64(2)(d)). The Special Education Policy Manual (Department of Education and Culture, 2008) provides further clarification on the right to an appropriate education with qualified teachers in an inclusive environment. When the outcomes of the prescribed curriculum are either not appropriate or not attainable, a student may require an Individualized Program Plan (similar to an Individualized Educational Plan in the United States).

In Nova Scotia, classroom teachers, at times in collaboration with support teachers or specialists, are responsible for the development and implementation of Individualized Program 
Plans. TAs assist teachers by delivering programs and providing support to the students (e.g., prompting to attend), but are not responsible for teaching or program planning. Other key personnel involved in the education of children with special needs are (a) resource/learning centre teachers who work with individual students or small groups of students to provide individualized remediation; (b) school administrators (i.e., principals, vice principals) who are responsible for the teachers and support staff within their schools; and (c) Student Services personnel (e.g., psychologists, speech-language pathologists, behaviour specialists) who provide assessment and consultative services to the schools.

The current study took place in the Annapolis Valley Regional School Board (approximately 16,500 students within 41 schools) with approximately 980 full-time equivalent teachers and 800 support staff, of which 367 were TAs. The decision to collaborate with this school board was based on a number of factors, including the board's commitment to improving educational services provided to children with ASD and previous partnerships with health researchers.

\section{Stage 1: Focus Groups}

Three focus groups were conducted in order to understand and identify (a) challenges faced by educators in inclusive classroom settings, (b) strategies being implemented successfully, and (c) existing barriers to the effective education of students with ASDs in inclusive classroom settings. The focus groups were led by two facilitators (the first author of this paper and a research coordinator) and were held during pre-scheduled meetings at the school board. Each focus group lasted for 90 minutes. The first focus group was conducted with the Lead Resource Teachers $(n=$ 11), including resource teachers and learning centre teachers, all of whom provided educational support for students with ASD. A second focus group was conducted with the entire Student Services support staff $(n=12)$, consisting of school-based specialists such as speech-language pathologists, school psychologists, educational consultants, learning disability specialists, and behaviour consultants. The third focus group was held with school administrators $(n=10)$ who consisted of a representative advisory group of Principals and Vice Principals from the three levels (i.e., elementary, middle, and high schools) across the school board, selected by the Student Services Supervisor. Feedback from the focus group participants indicated that they enjoyed the opportunity to discuss the topic and felt it was an excellent way to begin to identify a strategy for developing structures that would enhance effective programming for children with ASD. The facilitators noted that there was active participation by the focus group members and a sense of camaraderie, as well as a high level of sensitivity and respectfulness among the members.

The content elicited in each focus group was structured around four topic areas (a) knowledge of ASD, (b) educational programming for children with ASD, (c) current effective local practices for students with ASD, and (d) needs and barriers to working effectively with students with ASD. Two methods were used to summarize the content of the focus groups: (a) comprehensive debriefing notes generated immediately following each group by the two facilitators and (b) a content analysis of transcribed focus group discussions, accomplished using Ethnograph software. These two methods yielded consistent results; the main themes of which are presented below. Most themes were consistent across the three focus groups and therefore attribution to a specific focus group is only noted when the theme was group-specific.

Knowledge of ASD. Formal education on ASD in the context of degree programs was rare for resource teachers and administrators, although Student Services staff reported specific training in their graduate professional programs. Resource teachers reported that they gained in- 
formation "on the job" in response to immediate needs (e.g., an incoming student or a new concern with a student). Frequently, students' parents as well as colleagues provided this information. Educators identified popular media, including the Internet, magazines, television, and radio as common sources of information. However, concerns regarding how to "filter through" information from popular media sources was expressed.

There was agreement across participants that knowledge of ASD was more common at the elementary than at the junior high or high school levels. Key areas highlighted for further professional development included raising awareness that ASD impacts functioning across all environments (i.e., has implications for all daily living functions, not just school), exploring ways to balance the needs of students with ASD and the needs of other students in the classroom, and identifying autism-specific programs that "fit" with the philosophy and practice of an inclusive school environment. Participants in all groups indicated that training in effective strategies should include hands-on learning opportunities and should be available when needed (i.e., when a child is diagnosed with ASD or enters a new classroom).

Educational programming. Although participants valued the program planning process, a major identified professional development need pertained to the skills required for the development of Individualized Program Plans. This need was identified as especially pronounced in non-academic areas (e.g., social skills, activities of daily living, behaviour support). Educational programming at the junior high and high school levels was noted as a particular challenge, as was planning for transitions between levels. There was agreement across the groups that more time was needed to be allocated to both the development and implementation of programs with a focus on ensuring consistency across settings.

Specific difficulties with educational programming included coordination and follow-up activities, discrepancies between the goals of programming and specific policies (e.g., discipline policy), consistency across settings and educators, and discrepant knowledge and skills between the teachers (who through legislation are responsible for programs) and TAs (who are often responsible for implementing programs). This discrepancy between knowledge and skills of teachers and TAs was believed to be the result of TAs having more focused professional development opportunities in the area of ASD. In Nova Scotia, TAs often have access to specific professional development opportunities regarding different developmental disorders such as ASD. Teacher professional development opportunities tend to focus on broader issues, such as teaching literacy skills, rather than on specific childhood disorders.

Current effective practices. Participants reported that a more systematic and coordinated provincial approach to early intervention for children with ASD has improved the transition into school. Some successes at the elementary school level were noted and attributed to increased availability of information and dedicated staff time, administrative support, and concerted efforts at multidisciplinary program planning. Participants expressed that visits to schools experiencing such success have been helpful to staff from other schools.

The focus group of lead resource teachers also noted that the operationalization of inclusion to mean that the child should be included in classroom activities "within their capabilities" rather than "all the time" has been a positive change. All participants across groups noted that having dedicated staff to help develop programs, and dedicated space in which to implement programs, is helpful. The importance of multidisciplinary teams was also highlighted, with a particular focus on the critical roles of speech-language pathologists and occupational therapists. 
Needs and barriers. Identified barriers to effective education for children with ASD included inflexible administrative policies or procedures (e.g., zero tolerance for aggressive behaviours), lack of resources (e.g., funding, space for materials or for program delivery, equipment and materials), and inconsistency of approaches (e.g., between teacher and TA). Focus group participants also identified the need for a designated individual responsible for coordination of the program across settings and educators, as well as the need for more direct services from non-education professionals (e.g., health care providers such as psychologists, occupational therapists, and physicians). A case management model, which would include a focus on school, home, and community, was frequently suggested as a way to overcome many of the barriers to effective programming for these children.

One common concern was the challenge of programming for children with ASD in a strictly inclusive school environment. Focus group participants expressed concern regarding the difficulty of meeting the developmental needs of children with ASD within the classroom setting which may include 30 or more other children who also have a range of needs requiring a number of individual programs or program adaptations. It was generally believed that one-time professional development opportunities are not as effective as ongoing multilevel in-service opportunities (i.e., in-service opportunities ranging from didactic materials such as information booklets to hands-on teaching experiences such as visiting model classrooms). In summary, educators identify an over-arching need for timely information, expert consultation, and the coordination of education and health services.

\section{Stage 2: Surveys}

We used focus group results to design a survey questionnaire. Its purpose was to determine the preferred methods of delivering information required by educators to enhance the provision of educational services to children with ASD. The questionnaire developed was administered to a representative sample of teachers $(n=175)$ and TAs $(n=50)$ selected from 13 schools $(49 \%$ elementary, $51 \%$ middle/high schools). Respondents' years of teaching experience ranged widely with the teacher group, having an average of 18 years of experience (range 1 to 34) and the TA group a mean of 9 years of experience (range 1 to 27 ).

For analyses, quantitative data from the survey were divided into four sections, representing informant responses to (a) learning opportunities regarding teaching children with ASD, (b) comfort level in supporting children with ASD in an inclusive educational context, (c) perceived professional development needs, and (d) challenges and successes in supporting children with ASD in the education system. The survey included 2 demographic questions (role in school system, years working in the education system), 11 questions about learning opportunities, 7 questions about comfort level, 10 questions about professional development needs, and 3 questions about challenges and successes. The questions included a range of response formats from Likert scale questions to open-ended questions. The questions and response format are described in the sections that follow and in the Tables. Results from each of the four sections are described below. We also examined the correlation between years of experience and comfort level in supporting children with ASD in an inclusive educational context. This was thought to be of interest as it may be that years of working within an education system could contribute to teachers' and TAs' comfort level in supporting children with ASD.

Learning opportunities regarding teaching children with ASD. Teachers and

TAs indicated whether they had participated in 11 different types of possible learning opportuni- 
ties about ASD. TAs reported more learning opportunities than teachers across the majority of formats addressed (i.e., courses, readings, mentoring, in-services provided at the school board and provincial Department of Education levels, workshops outside the education system, as well as hands-on training). The only areas in which the two groups did not differ concerned accessing information from the media (e.g., TV, Internet, newspapers), parents of children with ASD, and through personal associations such as friends and family members (see Table 1).

Teachers were reportedly less likely to have specific ASD-relevant coursework than TAs during their initial training. Although $57.1 \%$ of teachers had taken a course on teaching children with special needs, which included information on ASD, only $7.1 \%$ had a class solely focused on the education of students with ASD. In contrast, $85.4 \%$ of TAs had a course on teaching students with special needs (with information on ASD), and 34.8\% had an entire course on the education of students with ASD during their initial training. Moreover, TAs were far more likely than teachers to have had professional development opportunities for workshops on ASD and related interventions, whether provided by the school board (77.6\% vs. $37.5 \%$, respectively), the Department of Education (37.5\% vs. $15.1 \%$, respectively), or outside agencies (46.9\% vs. $23.4 \%$, respectively). When considering learning opportunities beyond traditional classroom experiences, TAs reported that their primary information sources were from exchanges with colleagues $(97.9 \%)$, the media $(87.5 \%)$, and hands-on training experiences $(85.4 \%)$. For teachers, primary sources were the media (90.5\%), colleagues (78.3\%), and parents of children with ASD (67.9\%).

Teachers and TAs were also asked to rate the usefulness of each of the professional development activities (see Table 1). Generally, ratings fell in the mid-range on a scale of 0 (not useful) to 4 (very useful) for both teachers and TAs. However, teachers tended to provide lower ratings, indicating that they found these activities less useful than did TAs. Both groups reported that the most useful learning experiences were hands-on training, mentoring by experienced colleagues, and workshops (including those held by the school board and those held by agencies outside of the school board).

Table 1

Learning Opportunities for Teachers and Teacher Assistants

\begin{tabular}{|c|c|c|c|c|c|c|}
\hline & \multicolumn{3}{|c|}{ Experience (\% Yes) } & \multicolumn{3}{|c|}{ Usefulness $(M)$} \\
\hline & Teachers & TAs & $x^{2}$ & Teachers & TAs & $F$ \\
\hline $\begin{array}{l}\text { A least one full course focused on ASD during your } \\
\text { formal training }\end{array}$ & 7.1 & 34.8 & $24.6^{*}$ & 2.5 & 3.2 & 2.86 \\
\hline $\begin{array}{l}\text { A course focused on special needs which included } \\
\text { information about ASD }\end{array}$ & 57.1 & 85.4 & $12.9^{*}$ & 2.3 & 2.8 & $9.06^{*}$ \\
\hline Media such as television, internet, newspapers & 90.5 & 87.5 & 0.4 & 2.0 & 2.3 & $5.75^{*}$ \\
\hline Parents of your students with ASD & 67.9 & 80.9 & 3.0 & 2.6 & 2.8 & 1.42 \\
\hline Colleagues with more training/experience & 78.3 & 97.9 & $10.0^{*}$ & 2.9 & 3.2 & $4.02^{*}$ \\
\hline Board in-services focused on ASD & 37.5 & 77.6 & $24.4^{*}$ & 2.9 & 3.1 & 1.75 \\
\hline Provincial (Dept. of Ed.) PD opportunities on ASD & 15.1 & 37.5 & $11.7^{*}$ & 2.5 & 3.1 & $5.08^{*}$ \\
\hline Workshops outside of the school board/Dept. of Ed. & 23.4 & 46.9 & $10.3^{*}$ & 3.0 & 3.4 & 3.62 \\
\hline Personal associations (friends, family) & 43.1 & 56.0 & 2.6 & 2.6 & 3.0 & $5.37^{*}$ \\
\hline $\begin{array}{l}\text { Hands-on training (shadowing, visiting other } \\
\text { programs/schools) }\end{array}$ & 28.6 & 85.4 & $49.8^{*}$ & 2.9 & 3.5 & $11.78^{*}$ \\
\hline Specific books, videos, etc. & 53.3 & 81.6 & $12.7^{*}$ & 2.6 & 2.9 & 1.91 \\
\hline
\end{tabular}


Comfort level in supporting children with ASD in an educational context. Respondents were asked to rate their comfort level on a 5-point Likert scale $(0=$ low comfort level to $4=$ high comfort level) in a number of domains related to supporting children with ASD (see Table 2). Across the seven domains, TAs consistently reported greater comfort than did teachers. The mean teacher ratings fell in the low end of the "moderate comfort level" range, whereas the mean TA ratings were in the high end of the "moderate comfort level" range. Thus, while TAs endorsed a higher comfort level compared to teachers, both groups were reporting comfort levels within the moderate range. The largest difference between the ratings of teachers and TAs was in their overall comfort level in supporting children with ASD, with TAs providing ratings about $25 \%$ higher than those of teachers.

Interestingly, both groups reported a greater comfort level in program planning for children with special needs other than ASD than for children with ASD. Contrary to the focus group results, the teachers and TAs did not report lower levels of comfort in programming for nonacademic (i.e., social/emotional, behavioural, and life skills) compared to academic skills. Again, TAs reported a greater comfort level than did teachers, but there was little difference within each group in their ratings of programming for academic and non-academic areas.

Correlational analyses indicated that comfort level in supporting children with ASD was not related to years of experience $(r=-.10, p=.14)$ either for teachers or TAs. Instead, higher comfort levels were related to in-service or professional development opportunities, including reading materials related to the education of students with ASD $(r=.50, p<.001)$, hands-on training experiences $(r=.47, p<.001)$, school board in-services $(r=.45, p<.001)$, learning from parents of children with ASD $(r=.38, p<.001)$, workshops outside the education system $(r$ $=.37, p<.001)$, special education courses with some ASD content $(r=.34, p<.001)$, Department of Education in-services on ASD $(r=.30, p<.001)$, mentoring from colleagues $(r=.26, p$ $<.001)$, courses on ASD $(r=.24, p<.001)$, and personal associations $(r=.18, p=.007)$. Interestingly, the media, the primary source of information for teachers and the second highest ranked source for TAs, was the only learning opportunity not associated with higher comfort levels in supporting students with $\operatorname{ASD}(r=.09, p=.17)$.

Table 2

Comfort in Supporting Children with ASD in the Educational System

\begin{tabular}{|c|c|c|c|}
\hline & $\begin{array}{c}\text { Teachers } \\
M(S D)\end{array}$ & $\begin{array}{c}\text { TAs } \\
M(S D)\end{array}$ & $F$ \\
\hline $\begin{array}{l}\text { How would you rate your overall comfort level in supporting children with } \\
\text { ASD in an educational context? }\end{array}$ & $2.01(1.05)$ & $3.12(0.78)$ & $47.72^{*}$ \\
\hline $\begin{array}{l}\text { How would you rate your level of comfort with the program planning } \\
\text { process for children with special needs? }\end{array}$ & $2.25(1.01)$ & $2.63(0.91)$ & $5.46^{*}$ \\
\hline $\begin{array}{l}\text { How would you rate your level of comfort with the program planning } \\
\text { process for children with ASD? }\end{array}$ & $1.75(1.08)$ & $2.38(1.10)$ & $12.51^{*}$ \\
\hline $\begin{array}{l}\text { Please rate your comfort level in planning programs for children with ASD } \\
\text { in the area of academics }\end{array}$ & 1.77 (1.05) & $2.23(1.07)$ & $7.29^{*}$ \\
\hline $\begin{array}{l}\text { Please rate your comfort level in planning programs for children with ASD } \\
\text { in the area of social/emotional }\end{array}$ & $1.72(1.08)$ & 2.32 (1.07) & $11.43^{*}$ \\
\hline $\begin{array}{l}\text { Please rate your comfort level in planning programs for children with ASD } \\
\text { in the area of behaviour }\end{array}$ & $1.66(1.05)$ & $2.30(1.08)$ & $13.24^{*}$ \\
\hline $\begin{array}{l}\text { Please rate your comfort level in planning programs for children with ASD } \\
\text { in the area of life skills }\end{array}$ & $1.74(1.06)$ & $2.34(1.05)$ & $13.85^{*}$ \\
\hline
\end{tabular}


Perceived professional development needs. Respondents were asked to rate on a 5-point Likert scale $(0=$ none to $4=a$ lot $)$ the perceived usefulness of 10 different content areas for professional development (see Table 3). Unlike the findings for learning opportunities and comfort levels, teachers and TAs did not differ in their perceptions of professional development needs, with the exception of transition planning, which TAs rated as more useful than teachers. Both groups rated the 10 content areas similarly in terms of usefulness (with mean ratings around 3 ), indicating a need for training across multiple areas ranging from general knowledge of ASD (e.g., implications for academic, social/emotional, behavioural, and life skills), program planning and implementation, integration of programs within the classroom, transition planning, and planning in inclusive school environments.

When asked to identify preferred modes of delivery to meet their professional development needs, responses were generally consistent across both groups, with the exception of hands-on experiences, which were rated more favourably by TAs. The preferred delivery mode was a series of workshops; teachers next favoured one-time workshops while TAs favoured hands-on training experiences. The least preferred delivery method for both groups was support materials such as books and videos.

Preferred delivery modes also varied with the content area. One-time workshops were preferred for general information about ASD and transition planning, whereas workshop series was preferred for learning needs across developmental domains (i.e., academic, social/emotional, behavioural, life skills) and for program planning and implementation generally and within inclusive school settings. TAs preferred hands-on training experiences for general program implementation, including integration of the program plan within ongoing class activities.

Challenges and successes in supporting children with ASD in the education system. Summaries of responses to the three open-ended questions are provided below.

What are the greatest challenges for you in supporting children with ASD? Both groups identified that the greatest challenges in supporting children with ASD included (a) not enough time for program planning; (b) not enough support in terms of TAs, resource teachers, other specialists, materials, and space; (c) constraints resulting from large classes; (d) the diversity and nature of individual children's needs, including behaviour issues; and (e) a lack of in-service opportunities and timely access to ASD information.

Table 3

Usefulness of Professional Development Across Topic Areas

\begin{tabular}{lccc}
\hline & Teachers & TAs & \\
& $M(S D)$ & $M(S D)$ & $F$ \\
\hline Understanding the nature of ASD & $3.01(1.08)$ & $3.30(0.83)$ & 2.79 \\
Academic learning needs & $3.20(0.91)$ & $3.09(0.80)$ & 0.57 \\
Social/Emotional needs & $3.33(0.86)$ & $3.56(0.65)$ & 3.00 \\
Behavioural needs & $3.42(0.82)$ & $3.60(0.68)$ & 2.01 \\
Life skills needs & $3.11(0.98)$ & $3.38(0.80)$ & 3.02 \\
Program planning process for ASD & $3.14(0.91)$ & $3.04(0.98)$ & 0.36 \\
Program implementation & $3.13(0.94)$ & $3.15(0.86)$ & 0.02 \\
Integration of program with ongoing class activities & $3.26(0.91)$ & $3.26(0.80)$ & 0.00 \\
Transition planning (grade to grade, school to school) & $2.79(1.07)$ & $3.15(0.91)$ & $4.27^{*}$ \\
Programming in an inclusive environment & $2.96(1.06)$ & $3.26(1.11)$ & 2.70 \\
\hline Note. Scale: $=$ = none 2 = some 4 = a lot & & &
\end{tabular}

Note Scale: $0=$ none, 2 = some, $4=$ a lot

${ }^{*} p<.05$. 
In your opinion, what is working well in the education system in supporting children with ASD? As a group, teachers reported that the support of TAs was working well for them. Additionally, both teachers and TAs highlighted the importance of other professionals (e.g., speech-language pathologists, school psychologists, resource teachers), parent input, school board level support, and resource materials. Both groups also reported that a team approach was working well and that the earlier identification of children with ASD has been helpful.

Money aside, what would make the most difference in supporting children with ASD? Both teachers and TAs reported that support, in any form, and access to information (via in-service, shadowing, and from parents) would make the most difference in educating children with ASD. Other areas identified were time for preparation and planning, observing, and reporting about these children; reduced class sizes; and increased home-school communication. Planning time and reduced class sizes were not raised by TAs, perhaps because these issues are non-negotiable in their jobs.

\section{Discussion}

The primary objective of this mixed methods study was to identify educators' needs regarding professional development in order to determine how best to support them in providing quality programming for children with ASD within an inclusive educational system. For this purpose, researchers from Dalhousie University partnered with the Nova Scotia Department of Education and one of its school boards (Annapolis Valley Regional School Board). Information was collected through focus groups with key school board informants (i.e., lead resource teachers, Student Services staff, and administrators) and a survey of teachers and TAs. Multiple data collection methods was used: document analysis, focus groups for key informants, and survey methods for a larger sample. Use of focus group methodology informed the development of the survey, as well as addressed logistical restraints (e.g., large number of teachers and TAs, difficulty in obtaining relief time for their participation in focus groups). The results across the data collection methods indicate that educators perceive numerous successes, but also many barriers to providing optimal educational programming for children with ASD within an inclusive education system.

Each Canadian province is responsible for the development of its own special education policies. Nova Scotia, like most other provinces, supports the philosophy of inclusive education. Our research indicates that educators have found it difficult to meet the various wide-ranging needs of children with ASD within a strictly defined model of inclusive education. It should be noted that educators' perception of the stringency of this model is often contrary to the provincial philosophy, which highlights a continuum of supports, services, and settings to meet individual children's learning needs. Such challenges of educating children with ASD within an inclusive model are not unique to Nova Scotia, but rather have been reported in other provinces and countries (McGregor \& Campbell, 2001; Renty \& Roeyers, 2005; Wong, 2002).

Perceived competence in educating children with ASD within an inclusive model was related to the educators' level of knowledge and not to their years of teaching experience. Elsewhere, pilot research with educators has indicated that such perceptions of knowledge of ASD do not correspond with the accuracy of that perceived knowledge. Indeed, in that study, educators working directly with children with ASD demonstrated low levels of factual knowledge about the treatment of ASD (Williams, Schroeder, Carvalho, \& Cervantes, 2011). Interestingly, in the present study those with direct responsibility for the education of children with ASD (i.e., classroom teachers) reported having the least formal education in the education 
of students with ASD and felt the least comfortable in this role. A limitation of our study is that we could have defined 'courses' more specifically in order to improve our ability to differentiate levels of formal education. Nonetheless, TAs, who often deliver the individualized programs, were found to have the most training in ASD and higher comfort in working with children with ASD, yet are not involved in developing programs for specific children. It is important to note that TAs do not have the training to develop Individualized Program Plans, but perhaps their input into this process is warranted. Future research should examine why TAs have greater comfort in working with children with ASD. Potentially, this could be related to additional training, the type of training they receive, and more direct experiences working with children with ASD. Previous research has examined the role of paraprofessionals and has raised concern about training these individuals without providing corresponding training for the classroom teacher (Giangreco \& Broer, 2005; Marks, Schrader, \& Levine, 1999). Of importance, both classroom teachers and TAs in this study placed a high priority on additional training to enhance their ability to teach children with ASD.

How educators obtain knowledge about ASD was discrepant across groups. TAs and Student Services personnel reported more formal educational experiences (e.g., courses, workshops) than did teachers. Also, discrepancies were reported within groups across school levels, with greater knowledge and competence evident in school personnel working in the elementary grades compared to junior and senior high schools. Formal educational experiences were not perceived as the most influential on actual educational practice, but rather informal sources, such as information from colleagues, parents of children with ASD, and the popular media, were considered the primary source of information on ASD. Concerns about the accuracy of information provided by popular media (e.g., television and the Internet) were consistently expressed, and this primary source was not related to educators' comfort levels with educating children with ASD. As reported previously, and recognizing the potential for misinformation and misconceptions (Stone \& Rosenbaum, 1988), parents and colleagues were viewed as valuable information resources for educators. These results emphasize the critical role of effective collegial teamwork and strong parent-educator relationships in supporting the education of children with ASD.

Consistent with previous reports on educators' training needs (i.e., Dow \& Mehring, 2001; Helps, Newsom-Davis, \& Callias, 1999; Scheuermann, Webber, Boutot, \& Goodwin, 2003), all focus group participants indicated a need for additional training in the education of students with ASD. Training needs identified in the current study covered the full range from general information on ASD to specifics regarding program development and implementation. In fact, educators noted that they felt more comfortable with their knowledge level and programming skills for children with developmental disabilities other than ASD. Educators' preferences for the format by which information is delivered was dependent on content area, with this ideally customized to the information/skills being imparted to the educators. For general information about ASD, onetime workshops were seen as appropriate, but for programming, multileveled (e.g., a series of workshops) and applied experiences (e.g., direct, hands-on coaching and mentoring) were favoured. Of particular note, videos and books were not a preferred format for any of the content areas. Critical here is that educators' training needs focused on programming across the range of academic and non-academic skill/developmental domains in inclusive settings. The importance of enhancing educators' awareness and skill development is underscored by reports of a large gap between research/evidence-based methods and education practice (Iovannone, Dunlap, Huber, \& Kincaid, 2003; Volkmar, Reichow, \& Doehring, 2011). 
All focus group participants reported that they valued the existing individual program planning process but that additional training was required. Educators who interact on a daily basis with children with ASD reported equal competence in programming across the developmental/skill domains, whereas specialists identified a particular need for training on nonacademic programming. Most importantly, educators consistently emphasized the need for multileveled and multipronged professional development and consultation that is accessible in a timely fashion and as needs arise. They also identified the need for multidisciplinary teams, expert consultation, and dedicated time for program development and evaluation.

Concerns focused on the coordination of education and health services, such as those provided by outside agencies (e.g., medical care, neuropsychological assessment, specific mental health interventions), as well as follow-up services. Participants indicated that the provincial early intervention program has successfully coordinated services for younger students transitioning into public schools but noted that transition supports for students moving from elementary to junior high, and junior high to high school, as well as ultimately to adult services, are lacking. Another major concern was the discrepancy in knowledge and skills among the many school professionals who work with children with ASD, which results in inconsistent delivery of programs across settings and educators. Additional concerns focused on discrepancies between school policies and educational goals for these children (e.g., zero tolerance policies regarding aggressive behaviour). Finally, many educators identified the limited resources and space for programming to be significant barriers in optimizing the education of children with ASD.

Given the nature of this study, we cannot generalize our results to other provinces or countries (or indeed, to other school boards). However, research conducted elsewhere indicates that educators in other settings experience similar challenges when working within an inclusive education model (McGregor \& Campbell, 2001; Renty \& Roeyers, 2005; Wong, 2002). Further research is needed to identify and examine ways of providing more effective professional development for teachers and TAs that will help develop knowledge and comfort with programming for children with ASD within inclusive educational settings. This is important not only for the well-being of the children with ASD, but also for the well-being of the educators who support these children in the school system. This is particularly important as this group of educators have been reported to have higher rates of burnout (Hastings \& Brown, 2002; Jennett, Harris, \& Mesibov, 2003), particularly in the area of emotional exhaustion. For example, Myles, Ormsbee, and Simpson (1991) found that approximately 50\% of teachers of children with ASD were experiencing high stress and burnout in this area. Another area for future investigation is to examine perceived versus actual knowledge for teachers and TAs. This is important as there is some research that demonstrates that perceived knowledge (i.e., reported knowledge on a questionnaire) may not be highly related to actual knowledge (i.e., based on a test or observations of skills). For example, Ruble, Walters, Yu, and Setchel (2001) found that therapists reported greater knowledge of child development than what was evident on a test of their knowledge in this area.

The results of this study highlight the successes of educators in teaching children with ASD within inclusive classroom settings, yet also speak to the many barriers they face in providing the best possible programming for these children. Modified models, such as those incorporating case management (as suggested by our sample of educators), need to be evaluated to determine how to best deliver services to children with the full range of presentations of ASD so they can learn with their age-matched peers in inclusive educational settings. The need for evidence-based educational programs for students with ASD that can be implemented within inclusive educational settings has been emphasized previously and some have been evaluated (e.g., 
Hall, Grundon, Pope, \& Romero, 2010; Lerman, Vorndran, Addison, \& Kuhn, 2004; Robinson, 2011). Information such as we have provided here may help to tailor such models both to the needs of students with ASD and to those of the educators who serve them. Future research should focus on determining how to provide educators, including teachers and TAs, with the right information, at the right time, and in the right format so that they can deliver evidencebased effective education for children with ASD within inclusive classroom settings.

\section{References}

Autism and Developmental Disabilities Monitoring Network Surveillance Year 2008 Principal Investigators; Centers for Disease Control and Prevention. (2012). Prevalence of autism spectrum disorders: Autism and Developmental Disabilities Monitoring Network, 14 sites, United States, 2008. MMWR Surveillance Summary, 61(3), 1-19.

Baer, D. M., Wolf, M. M., \& Risley, T. R. (1968). Some current dimensions of applied behavior analysis. Journal of Applied Behavior Analysis, 1(1), 91-97. doi:10.1901/jaba.1968.1-91

Baer, D. M., Wolf, M. M., \& Risley, T. R. (1987). Some still-current dimensions of applied behavior analysis. Journal of Applied Behavior Analysis, 20(4), 313-327. doi:10.1901/jaba.1987.20-313

Barnett, C., \& Monda-Amaya, L. E. (1998). Principals' knowledge of and attitudes toward inclusion. Remedial and Special Education, 19, 181-192. doi:10.1177/074193259801900306

Bryson, S. E., Rogers, S. J., \& Fombonne, E. (2003). Autism spectrum disorders: Early detection and intervention, education and psychopharmacological treatment. Canadian Journal of Psychiatry, 48, 506-516. Retrieved from http://www.cpa-apc.org/index.php

Callahan, K., Henson, R. K., \& Cowan, A. K. (2008). Social validation of evidence-based practices in autism by parents, teachers, and administrators. Journal of Autism and Developmental Disorders, 38(4), 678692. doi:10.1007/s10803-007-0434-9

Department of Education and Culture. (2008). Special education policy: Nova Scotia. Retrieved from http://www.studentservices.ednet.ns.ca/sites/default/files/speceng.pdf

Dow, M. J., \& Mehring, T. A. (2001). Inservice training for educators of individuals with autism. Autism Spectrum Disorders: Educational and Clinical Interventions, 89-107. doi:10.1016/S0270-4013(01)80009-X

Education Act, Statutes of Nova Scotia. (1995-1996). Retrieved from http://nslegislature.ca/legc/statutes /eductn.htm

Elsabbagh, M., Divan, G., Koh, Y-J., Kim, Y. S., Kauchali, S., Marcín, C.,...Fombonne, E. (2012). Global prevalence of autism and other pervasive developmental disorders. Autism Research, 5, 160-179. doi:10 $.1002 /$ aur.239

Emam, M. M., \& Farrell, P. (2009). Tensions experienced by teachers and their views of support for pupils with autism spectrum disorders in mainstream schools. European Journal of Special Needs Education, 24(4), 407-422. doi:10.1080/08856250903223070

Giangreco, M. F., \& Broer, S. (2005). Questionable utilization of paraprofessionals in inclusive schools: Are we addressing symptoms or causes? Focus on Autism and Other Developmental Disabilities, 20, 10-26. doi:10.1177/10883576050200010201

Hall, L. J., Grundon, G., Pope, C., \& Romero, A. (2010). Training paraprofessionals to use behavioral strategies when educating learners with autism spectrum disorders across environments. Behavioral Interventions, 25(1), 37-51. doi:10.1002/bin.294

Hastings, R. P., \& Brown, T. (2002). Coping strategies and the impact of challenging behaviours on special educators' burnout. Mental Retardation, 40, 148-156. doi:10.1352/00476765(2002)040<0148:CSATIO $>2.0 . \mathrm{CO} ; 2$

Helps, S., Newsom-Davis, I. C., \& Callias, M. (1999). Autism: The teacher's view. Autism, 3, 287-298. doi:10 $.1177 / 1362361399003003006$

Horner, R. H., Carr, E. G., \& Strain, P. S. (2002). Problem behavior interventions for young children with autism: A research synthesis. Journal of Autism and Developmental Disorders, 32, 423-446. doi:10.1023 /A:1020593922901

Humphrey, N. (2008). Including pupils with autistic spectrum disorders in mainstream schools. Support for Learning, 23, 41-47. doi:10.1111/j.1467-9604.2007.00367.x 
Iovannone, R., Dunlap, G., Huber, H., \& Kincaid, D. (2003). Effective educational practices for students with autism spectrum disorders. Focus on Autism and Other Developmental Disabilities, 18, 150-165. doi:10 $.1177 / 10883576030180030301$

Jennett, H. K., Harris, S. L., \& Mesibov, G. B. (2003). Commitment to philosophy, teacher efficacy, and burnout among teachers of children with autism. Journal of Autism and Developmental Disorders, 33, 583593. doi:10.1023/B:JADD.0000005996.19417.57

Jerlinder, K., Danermark, B., \& Gill, P. (2010). Swedish primary-school teachers' attitudes to inclusion-The case of PE and pupils with physical disabilities. European Journal of Special Needs Education, 25, 4557. doi:10.1080/08856250903450830

Kavale, K. A., \& Forness, S. R. (1999). Efficacy of special education and related services. Washington, DC: American Association on Mental Retardation.

Lerman, D. C., Vorndran, C. M., Addison, L., \& Kuhn, S. (2004). Preparing teachers in evidence-based practices for young children with autism. School Psychology Review, 33(4), 510-526. Retrieved from http://www.nasponline.org/publications/spr/index-list.aspx

Lord, C., \& Jones, R. M. (2012). Re-thinking the classification of autism spectrum disorders. Journal of Child Psychology and Psychiatry, 53(5), 490-509. doi:10.1111/j.1469-7610.2012.02547.x

Marks, S. U., Schrader C., \& Levine, M. (1999). Paraeducator experiences in inclusive settings: Helping, hovering, or holding their own? Exceptional Children, 65, 315-328. Retrieved from http://journals.cec .sped.org/ec/

McGregor, E., \& Campbell, E. (2001). The attitudes of teachers in Scotland to the integration of children with autism into mainstream schools. Autism, 5, 189-207. doi:10.1177/1362361301005002008

Myles, B. S., Ormsbee, C. K., \& Simpson, R. L. (1991). Autism and stress: An individualized intervention plan for teachers. Focus On Autistic Behavior, 6(3), 8-16. doi:10.1177/108835769100600302

National Autism Center. (2009a). Evidence-based practice and autism in the schools: A guide to providing appropriate interventions to students with autism spectrum disorders. Retrieved from http://www .nationalautismcenter.org/nsp/

National Autism Center. (2009b). National Standards Project: Addressing the need for evidence-based practice guidelines for autism spectrum disorders. Retrieved from http://www.nationalautismcenter.org/nsp/

National Research Council. (2001). Educating children with autism. Washington, DC: National Academies Press.

Odom, S. L., Boyd, B. A., Hall, L. J., \& Hume, K. (2010a). Evaluation of comprehensive treatment models for individuals with autism spectrum disorders. Journal of Autism and Developmental Disorders, 40, 425436. doi:10.1007/s10803-009-0825-1

Odom, S. L., Boyd, B. A., Hall, L. J., \& Hume, K. (2010b). Erratum to: Evaluation of comprehensive treatment models for individuals with autism spectrum disorders. Journal of Autism and Developmental Disorders, 40, 437. doi:10.1007/s10803-009-0873-6

Osborne, L. A., \& Reed, P. (2011). School factors associated with mainstream progress in secondary education for included pupils with autism spectrum disorders. Research in Autism Spectrum Disorders, 5, 12531263. doi:10.1016/j.rasd.2011.01.016

Praisner, C. L. (2003). Attitudes of elementary school principals toward the inclusion of students with disabilities. Exceptional Children, 69, 135-145. Retrieved from http://journals.cec.sped.org/ec/

Reed, P., Osborne, L. A., \& Waddington, E. M. (2012). A comparative study of the impact of mainstream and special school placement on the behaviour of children with Autism Spectrum Disorders. British Educational Research Journal, 38(5), 749-763. doi:10.1080/01411926.2011.580048

Renty, J., \& Roeyers, H. (2005). Satisfaction with formal support and education for children with autism spectrum disorder: The voices of the parents. Child: Care, Health \& Development, 32, 371-385. doi:10 $.1111 /$ j.1365-2214.2006.00584.x

Rispoli, M., Neely, L., Lang, R., \& Ganz, J. (2011). Training paraprofessionals to implement interventions for people autism spectrum disorders: A systematic review. Developmental Neurorehabilitation, 14(6), 378-388. doi:10.3109/17518423.2011.620577

Robinson, S. (2011). Teaching paraprofessionals of students with autism to implement pivotal response treatment in inclusive school settings using a brief video feedback training package. Focus On Autism And Other Developmental Disabilities, 26(2), 105-118. doi:10.1177/1088357611407063 
Ruble, N., Walters, C., Yu, Y., \& Setchel, K. (2001). Actual versus perceived knowledge of child development in a therapeutic context: A survey of therapists. American Journal of Family Therapy, 29(3), 173-180. doi:10.1080/019261801750424299

Salend, S. J., \& Duhaney, L. M. G. (1999). The impact of inclusion on students with and without disabilities and their educators. Remedial and Special Education, 20(2), 114-126. doi:10.1177/074193259902000 209

Scheuermann, B., Webber, J., Boutot, A., \& Goodwin, M. (2003). Problems with personnel preparation in autism spectrum disorders. Focus on Autism and Other Developmental Disabilities, 18, 197-206. doi:10 $.1177 / 10883576030180030801$

Stone, W. L., \& Rosenbaum, J. L. (1988). A comparison of teacher and parent views of autism. Journal of Autism and Developmental Disorders, 18, 403-414. doi:10.1007/BF02212195

Swiezy, N., Stuart, M., \& Korzekwa, P. (2008). Bridging for success in autism: Training and collaboration across medical, educational, and community systems. Child and Adolescent Psychiatric Clinics of North America, 17, 907-922. doi:10.1016/j.chc.2008.06.001

Volkmar, F. R., Reichow, B., \& Doehring, P. (2011). Evidence-based practices in autism: Where we are now and where we need to go. In B. Reichow, P. Doehring, D. V. Cicchetti, \& F. R. Volkmar (Eds.), Evidence-based practices and treatments for children with autism (pp. 365-391). New York, NY: Springer Science + Business Media.

Williams, K. L., Schroeder, J. L., Carvalho, C., \& Cervantes, A. (2011). School personnel knowledge of autism: A pilot survey. The School Psychologist. Retrieved from http://www.apadivisions.org/division-16 /publications/newsletters/school-psychologist/2011/04/autism.aspx.

Wong, D. K. P. (2002). Struggling in the mainstream: The case of Hong Kong. International Journal of Disability, Development and Education, 49, 79-94. doi:10.1080/10349120120115343

World Health Organization. (1946). Preamble to the constitution of the World Health Organization as adopted by the International Health Conference, New York, 19 June-22 July 1946; signed on 22 July 1946 by the representatives of 61 States (Official Records of the World Health Organization, no. 2, p. 100) and entered into force on 7 April 1948.

\section{Authors' Note}

Correspondence concerning this article should be addressed to Penny Corkum, Department of Psychology and Neuroscience, Dalhousie University, 1355 Oxford Street, PO Box 15000, Halifax, NS, Canada, B3H 4R2. Email: penny.corkum@dal.ca

Ann Power is now the Director, Youth Labour Market Attachment, Department of Labour and Advanced Education, Province of Nova Scotia. Kym Hume is now the owner of Autism Atlantic Consulting Services.

This work was supported by a grant from the Nova Scotia Health Research Foundation (CRA-2003-12). We would like to thank Maureen Balcom, Andre Benoit, Lorraine Chiasson, Karen Harvey, Robin Latta, Renee Lyons, Nancy Pynch-Worthylake, as well as all the participants in the focus groups and the educators who completed the survey. 